\title{
Cataract in chronic cluster headache: two case reports and review of the literature
}

\author{
Silvia Benemei · Paola Nicoletti · \\ Pierangelo Geppetti · Mara Bonciani
}

Received: 10 March 2008/ Accepted: 6 August 2008/Published online: 21 August 2008

(c) Springer-Verlag 2008

\begin{abstract}
Cluster headache $(\mathrm{CH})$ consists of attacks of severe, unilateral orbital/supraorbital/temporal pain, lasting for 15-180 min, occurring once or more times a day, and associated with ipsilateral conjunctival injection, lacrimation and other symptoms. Cataract is clouding of the lens of the eye causing a progressive and painless loss of vision. We describe the cases of two men (not relative, but with the same last name, which originates from north-eastern Italy) that in young adult age, after years of suffering from chronic $\mathrm{CH}$, developed cataract on the same side of the pain attacks. Patient 1 was diagnosed as having cataract 18 years after the onset of episodic (and subsequently chronic) $\mathrm{CH}$. Patient 2 began suffering from chronic $\mathrm{CH}$ at the age of 44 years and after 8 years he developed cataract. This is the first report of cataract in patient suffering of $\mathrm{CH}$ and occurring in the eye affected by the pain attack.
\end{abstract}

Keywords Cluster headache - Cataract - Pain . Degenerative disease

No financial support received.

S. Benemei · P. Nicoletti · P. Geppetti

Unit of Clinical Pharmacology, University of Florence,

Florence, Italy

P. Geppetti

Centre for the Study of Headache, University of Florence,

Florence, Italy

M. Bonciani

Headache Unit, Villa Maria Teresa, Florence, Italy

S. Benemei $(\bowtie)$

Department of Preclinical and Clinical Pharmacology, University of Florence, Viale Pieraccini 6, 50139 Florence, Italy

e-mail: silvia.benemei@unifi.it

\section{Introduction}

Cluster headache is a form of primary neurovascular headache, which consists of unilateral head pain that occurs in association with cranial autonomic features and, in most patients, has a striking circannual and circadian periodicity. Excruciating painful attacks are accompanied by restlessness or agitation, usually last less than $3 \mathrm{~h}$, and occur in bouts for a few months during which the patient has one or more crisis per day [1].

The International Headache Society defines cluster headache as attacks of severe, strictly unilateral pain which is orbital, supraorbital and temporal or in any combination of these sites, lasting for 15-180 min and occurring from once every other day to 8 times a day. The attacks are associated with one or more of the following, all of which are ipsilateral: conjunctival injection, lacrimation, nasal congestion, rhinorrhoea, forehead and facial sweating, miosis, ptosis, eyelid oedema [2]. Epidemiological data for the general population are scarce; only five studies have been carried out until now on cluster headache prevalence in the general population, with conflicting results (prevalence rates vary between 56 and 326 cases in every 100,000 inhabitants). A recent study on a sample representative of the Italian general population aged over 14 years, reported an estimated prevalence rate of 279/100,000 (95\% CI: 173 427), 227/100,000 (95\% CI: 104-431) in women and 338/ 100,000 (95\% CI: 175-592) in men [3].

Cataract is clouding (opacity) of the lens of the eye that causes a progressive, painless loss of vision. The first symptom of cataract is usually blurred vision. Other symptoms that may progressively appear are: glare, halos, double vision and perception of colours as more yellow and less vibrant. These visual difficulties in a variable period force the patient to the surgical intervention. Three 
different types of cataract can be identified on a histological basis: nuclear, cortical and posterior subcapsular. Prevalence of the three types of cataract differs, although all increase with age [4]. Investigations [5-8] on possible risk factors for the development of cataract, showed positive correlation with myopia, diabetes, smoking [9-11], use of systemic corticosteroids [12], exposition to UV-B [13], and other environmental factors, to which has to be added genetic predisposition [14]. However, it should be underlined that different degrees of correlation between distinct risk factors and the three types of cataract have been reported [6, 15].

Prevalence studies of age-related cataracts are hampered by the absence of a uniform grading system for cataract opacities, by differing definitions of visual impairment, and by additional coexisting ocular pathologies causing loss of vision. Nonetheless, the Framingham Eye Study [16] in 1977 reported that the proportion of people with age-related cataracts causing loss of vision of 20/30 (6/9) or worse was $15.5 \%$ for all ages and $45.9 \%$ for those older than 75 years. In the Beaver Dam Eye Study [17] in 1992, using a similar definition of loss of vision reported proportions were $38.8 \%$ for men and $45.9 \%$ for women older than 74 years. However, it is not clear if variations in frequency reflect methodological diversity or true differences between populations [18]. Interestingly, most of the cited studies analyzed the cataract prevalence in age groups which are substantially different from those of our two cases. One single study reported the prevalence of cataract at a younger age (40 years and older) [15] with identified risk factors for the three different histological types of cataract. This study showed age-specific rates of the different histological cataract type, by stratifying the population sample by age. Prevalence of $1 \%$ (cortical type), of $0.2 \%$ (nuclear type) and of $2.0 \%$ (posterior subcapsular) was reported in individuals between 40 and 49 years and a prevalence of $3.9 \%$ (cortical type) of $0.2 \%$ (nuclear type) and of $2.6 \%$ (posterior subcapsular) was reported in individuals between 50 and 59 years.

Here, we report two cases that both developed cataract before the age of 50 years on the side affected from the cluster headache and reviewed published similar cases and potential mechanisms for comorbidity.

\section{Case reports}

We present a 44-year-old man with a history of cluster headache, diagnosed in accordance with IHS guidelines [2], since he was 21 years old. Daily pain attacks, lasting about $90 \mathrm{~min}$, were localized to the left periorbital area with ipsilateral lacrimation and rinorrhea. The cluster headache that initially occurred sporadically, from the age of 43 years became chronic. At the age of 39 , the patient was diagnosed of cataract on the left eye that was in the same year treated by surgery. The sole risk factor for developing cataract at anamnesis was smoking habit (30 cigarettes/day). A detailed pharmacological anamnesis excluded any kind of exposure to prolonged treatment with steroid drugs.

The second case was a 53-year-old man who experienced his first cluster headache episode when he was 44 years old. Cluster periods were characterized by 3-4 attack/day of severe right-sided pain localized to the periorbital region, lasting about $45 \mathrm{~min}$ and associated to ipsilateral lacrimation. The cluster headache was chronic from onset. At the age of 50 the patient was diagnosed of cataract to the right eye that was treated by surgery. The reported risk factor for developing cataract was smoking habit (10 cigarettes/day). Also in this case, there was no report of chronic treatment with steroid drugs.

\section{Search strategy and selection criteria}

References were identified by searches of PubMed from 1966 until October 2007 with the terms "cluster headache" and "cataract". Only papers published in English were reviewed.

\section{Discussion}

Our search in PubMed shows only one report of a patient with cluster-like headache, which began after surgical removal of the crystalline for cataract and intraocular lens implant [19]. Therefore, to our knowledge, this is the first report of cataract occurring in cluster headache patients and, interestingly, on the same eye affected by the pain attack. It is of interest that both patients developed cataract in a young age, after suffering for years from chronic cluster headache attacks and in the absence of main risk factors for the development of early onset cataract, including prolonged steroid drugs exposure.

It is noteworthy that the two patients, although not relative, had the same, rather uncommon, last name that we found to be specifically represented in a defined area of north-eastern Italy. However, because we could not investigate the pedigree of one patient, any hypothetical genetic link between the uncommon occurrence of early onset cataract and cluster headache cannot be proposed. In addition, it was not possible to perform in either of the two patients any investigation on ocular inflammation. Thus, no speculation can be made on a possible causal relationship between repeated episodes of pain, inflammation and autonomic abnormalities that are considered to contribute 
to the cluster headache attack, and the precocious occurrence of the cataract. However, this first evidence of the occurrence of cataract in relatively young adult men with a history of chronic cluster headache is of importance, because underlining this uncommon type of comorbidity may favour the report of additional similar cases.

\section{Conflict of interest None.}

\section{References}

1. Goadsby PJ (2002) Pathophysiology of cluster headache: a trigeminal autonomic cephalgia. Lancet Neurol 1:251-257

2. (2004) The International Classification of Headache Disorders: 2nd edn. Cephalalgia 24:9-160

3. Torelli P, Castellini P, Cucurachi L et al (2006) Cluster headache prevalence: methodological considerations. A review of the literature. Acta Biomed 77:4-9

4. Acosta R, Hoffmeister L, Roman R et al (2006) Systematic review of population-based studies of the prevalence of cataracts. Arch Soc Esp Oftalmol 81:509-516

5. Giuffre G, Dardanoni G, Lodato G (2005) A case-control study on risk factors for nuclear, cortical and posterior subcapsular cataract: the Casteldaccia Eye Study. Acta Ophthalmol Scand 83:567-573

6. Delcourt C, Cristol JP, Tessier F et al (2000) Risk factors for cortical, nuclear, and posterior subcapsular cataracts: the POLA study. Pathologies Oculaires Liees a l'Age Am J Epidemiol 151:497-504

7. Mukesh BN, Le A, Dimitrov PN et al (2006) Development of cataract and associated risk factors: the Visual Impairment Project. Arch Ophthalmol 124:79-85
8. Abraham AG, Condon NG, West Gower E (2006) The new epidemiology of cataract. Ophthalmol Clin North Am 19:415425

9. Kelly SP, Thornton J, Edwards R et al (2005) Smoking and cataract: review of causal association. J Cataract Refract Surg 31:2395-2404

10. Krishnaiah S, Vilas K, Shamanna BR et al (2005) Smoking and its association with cataract: results of the Andhra Pradesh eye disease study from India. Invest Ophthalmol Vis Sci 46:58-65

11. Cumming RG, Mitchell P (1997) Alcohol, smoking, and cataracts: the Blue Mountains Eye Study. Arch Ophthalmol 115:1296-1303

12. Curtis JR, Westfall AO, Allison J et al (2006) Population-based assessment of adverse events associated with long-term glucocorticoid use. Arthritis Rheum 55:420-426

13. Delcourt C, Carriere I, Ponton-Sanchez A et al (2000) Light exposure and the risk of cortical, nuclear, and posterior subcapsular cataracts: the Pathologies Oculaires Liees a l'Age (POLA) study. Arch Ophthalmol 118:385-392

14. Hammond CJ, Snieder H, Spector TD et al (2000) Genetic and environmental factors in age-related nuclear cataracts in monozygotic and dizygotic twins. N Engl J Med 342:1786-1790

15. McCarty CA, Nanjan MB, Taylor HR (2000) Attributable risk estimates for cataract to prioritize medical and public health action. Invest Ophthalmol Vis Sci 41:3720-3725

16. Kahn HA, Leibowitz HM, Ganley JP et al (1977) The Framingham Eye Study. I. Outline and major prevalence findings. Am J Epidemiol 106:17-32

17. Klein BE, Klein R, Linton KL (1992) Prevalence of age-related lens opacities in a population. The Beaver Dam Eye Study. Ophthalmology 99:546-552

18. Asbell PA, Dualan I, Mindel J et al (2005) Age-related cataract. Lancet 365:599-609

19. Maggioni F, Dainese F, Mainardi F et al (2005) Cluster-like headache after surgical crystalline removal and intraocular lens implant: a case report. J Headache Pain 6:88-90 